\title{
Communicating efficacy: How the IPCC, scientists, and other communicators can facilitate adaptive responses to climate change without compromising on policy neutrality
}

\author{
Niall McLoughlin ${ }^{1}$ iD
}

Received: 14 January 2021 / Accepted: 24 September 2021 /Published online: 2 November 2021

(c) The Author(s) 2021

\begin{abstract}
The Intergovernmental Panel on Climate Change (IPCC) adopts a solution-oriented approach to communicating climate change, but does not advocate any specific mitigation or adaptation options. While this helps to maintain a neutral stance in relation to policy advocacy, this approach may also create reluctance amongst IPCC scientists to communicate affective information about climate change, which could help to facilitate behavioural and societal transitions to manage climate risks. Research from the social sciences demonstrates that communications can influence cognitive, affective, and behavioural engagement with climate change. Specifically, there is ample evidence that people's sense of 'efficacy' - beliefs about personal or collective capacity to respond, and effectiveness of responses - must be appealed to sufficiently alongside communication about the threats posed by climate change, to help facilitate mitigation and adaptation responses. This essay draws on a range of research findings to argue that the IPCC's scientists and communications personnel can nurture efficacy beliefs about climate change, without compromising on values of policy neutrality, or undermining public trust. Specifically, the essay draws on communications strategies related to vicarious learning, mastery experiences, highlighting success stories, and use of language and imagery, which have been shown to increase efficacy. The essay has implications for how IPCC scientists and the organisation as a whole engages with a range of audiences, and suggestions also have relevance for other communicators of climate change, such as governments, academics, journalists, health professionals, community leaders, and creative practitioners.
\end{abstract}

Keywords Efficacy $\cdot$ Communication $\cdot$ Framing $\cdot$ Language $\cdot$ Visuals

This article is part of the topical collection "Climate Change Communication and the IPCC", edited by Saffron O’Neill and Roz Pidcock.

Niall McLoughlin

niall.c.mcloughlin@bath.edu

1 Department of Psychology, University of Bath, Bath, UK 


\section{Introduction}

The Intergovernmental Panel on Climate Change (IPCC) is a globally significant voice on climate change. The way that the IPCC, scientists, and other communicators share information about climate change implicates how people engage with climate risks on cognitive, affective (i.e. emotional), and behavioural levels (Lorenzoni et al. 2007). Yet despite vast quantities of information communicated about climate change, government and societal responses do not yet address climate risks sufficiently. This essay responds to two issues that remain pervasive across the landscape of climate engagement, which, if addressed, can help to facilitate adaptive responses to climate change. The first issue is that communications have frequently highlighted the threats posed by climate change impacts, while insufficiently addressing peoples' sense of efficacy to respond. The second related issue concerns the hesitancy of IPCC scientists to communicate affective and motivational information about climate responses, even though this could help to bolster societal responses.

Responding to these issues, this essay sets out the basis for an approach to communicating climate change that places sufficient emphasis on addressing efficacy — that is, people's perceptions about their ability to take actions as individuals and groups, and the perceived effectiveness of responses. It is argued that appeals to efficacy are part of responsible climate change communication, and that efficacy can be fostered through communication without specific policy advocacy, unless this is deemed appropriate.

The IPCC is a multifaceted organisation comprising a broad interdisciplinary panel of experts in natural sciences, engineering, social sciences, and humanities, who synthesise peer-reviewed literature to produce reports. The body also involves organisational staff working to deliver outputs, and contributions from governments and experts as reviewers at certain stages in report cycles. The recommendations in this article are directed towards (a) IPCC scientists and authors, with an emphasis on their outreach activities with the public, policymakers, and other stakeholders, and (b) IPCC staff involved in communicating information about climate change to different audiences (e.g. via press releases, events, social media posts, and so on). Recommendations are likely to be especially salient for the IPCC's WGII (Impacts, Adaptation, and Vulnerability) and WGIII (Mitigation), given their focus on responses addressing climate risks.

Despite being oriented towards the IPCC, many of the recommendations in this essay can usefully be adopted by other types of communicators seeking to motivate responses to climate change including non-IPCC academics, journalists, health professionals, community leaders, and creative practitioners. Some suggestions may also be useful for members of the public engaging with family, friends, and peers about climate change.

\section{Why efficacy matters for both climate mitigation and adaptation}

For people to take action to reduce risks, research has frequently shown that individuals need to perceive both (a) a threat warranting a response and (b) sufficient efficacy to respond. Efficacy, as conceptualised in Social Cognitive Theory (SCT), concerns perceived competence in task-specific domains, and implicates how people think, feel, and motivate themselves (Bandura 1994). A heightened state of efficacy is non-avoidant, driving problem-focused, rather than avoidant, coping responses to threats, and helps to maintain behaviour changes in the long term. Supporting people's actual capacity to respond 
(agency), efficacy is considered to be a key agentic mechanism (Bandura 2018), and efforts to bolster efficacy can be thought of as a form of empowerment. Three key efficacy constructs are typically distinguished in social research: beliefs about one's personal ability to act (self-efficacy), beliefs about the effectiveness of actions (response-efficacy), and beliefs about the capacity of groups to carry out actions together (collective-efficacy). ${ }^{1}$ Each type has been associated with climate mitigation and adaptation.

Firstly, efficacy beliefs are important antecedents of climate mitigation. Through analysis of a large European dataset, Gregersen et al. (2021) show that - alongside feeling worried about climate change - personal efficacy, and beliefs about the outcomes of personal and collective responses, is associated with personal energy-saving behaviours. Bostrom et al. (2019) found that self-efficacy and response-efficacy beliefs (related to collective and governmental responses) were associated with greater public support for climate mitigation. This was the case even after controlling for ideology and beliefs about the causes of climate change. Similarly, Doherty and Webler (2016) report that amongst the most alarmed segment of the US population, self-efficacy, response-efficacy, and collective-efficacy are key factors associated with greater intentions to engage in civic behaviours related to climate change. And at the personal level, people's beliefs about the effectiveness of responses are associated with willingness to engage in actions (such as household energy behaviours), even if the actual effectiveness of the behaviour is much lower than perceived (Truelove and Parks 2012).

Secondly, in terms of climate adaptation and when people encounter climate hazards directly, efficacy beliefs are also consistently shown to predict adaptive responses. Metaanalysis of 106 studies across 23 different countries found self-efficacy and responseefficacy to have a very substantial influence on willingness to engage in climate adaptation relating to hazards such as flooding, wildfires, and drought (van Valkengoed and Steg 2019). Though it may be less relevant for individual-level behaviours, collective-efficacy has also been associated with willingness to engage in community-level adaptation activities, such as water conservation activities in India (e.g. Thaker et al. 2016).

Usefully for communication efforts, efficacy also appears to influence people's willingness to discuss climate change with others. Swim and Fraser $(2013,2014)$ demonstrate that environmental educators are more likely to engage with others about climate change when they feel capable of doing so, and when they believe it is possible for individuals to influence successful societal responses through discussion. Thus, an added benefit of bolstering efficacy is that subsequent communication and dialogue about climate change is made more likely.

Given climate change is simultaneously an individual-level and collective-level issue, there is debate around which forms of efficacy are most relevant in different situations (Koletsou and Mancy 2011). There is evidence that certain efficacy variables may better explain certain forms of climate mitigation and adaptation. For instance, Lubell (2002) reports that beliefs about collective benefits and outcomes underpin decision making in relation to group-based environmental action, rather than individual-level motives.

\footnotetext{
1 Note that some studies apply a framework by Koletsou and Mancy (2011) which further distinguishes between collective-efficacy (i.e. group ability) and collective outcome expectancy (i.e. group effectiveness). Efficacy in the political realm has also been distinguished at levels of internal (personal ability to engage), external (whether political representatives will respond to public calls for action), and response (effectiveness of political interventions - see Hart and Feldman 2014). Further efficacy constructs may also exist in the literature.
} 
Additionally, McLoughlin (2021) demonstrates that self-efficacy is particularly important for individual-level protective actions (e.g. property-level flood protection), response-efficacy for support of policy responses (e.g. support of new flood defences), and collectiveefficacy is most relevant where broad social changes are required (e.g. civic- and groupbased climate actions). Nevertheless, this does not mean that specific efficacy variables should be discounted altogether for certain climate responses, as they may interact and function together as well. For instance, collective-efficacy may stimulate engagement in group action by increasing self-efficacy beliefs (Jugert et al. 2016); and beliefs about personal and collective outcomes can be intercorrelated (Gregersen et al. 2021). Perceptions about personal-level actions may therefore be associated with judgements about other people taking similar actions and the potential for greater impact when acting collectively. It has also been noted that response-efficacy should be considered alongside self- and collective-efficacy beliefs to promote behavioural responses (Koletsou and Mancy 2011).

Crucially, if individuals have a heightened sense of threat, but have insufficient efficacy, maladaptive responses are made more likely (e.g. threat denial, avoidant coping, and fatalism). This pattern has been demonstrated for climate engagement (O'Neill et al. 2013; O'Neill and Nicholson-Cole 2009) echoing consistent findings in the field of health communication regarding the importance of both threat and coping appraisals (Floyd et al. 2000; Peters et al. 2013; Witte and Allen 2000). Consequentially, a lack of efficacy has been associated with lack of preparedness and negative wellbeing outcomes, such as stress and anxiety, in relation to climate hazards (Fox-Rogers et al. 2016; Walker-Springett et al. 2017). Thus, an important part of responsible risk communication is to ensure that audiences either have high levels of efficacy already or efficacy is sufficiently addressed, so individuals can respond adaptively to threats (Peters et al. 2013).

\section{Why climate communicators must address efficacy now}

While a combination of threat and efficacy beliefs appears to increase the likelihood that a person will take actions to address climate change, there is clear evidence that a balance between threat and efficacy has not been achieved in climate change communications to date. Analysis of the Summary for Policymakers (SPM) of the Synthesis Report (SYR) of the IPCC Fifth Assessment Report (AR5) has shown that threat information occurred much more frequently than efficacy-based information, with the latter tending to feature later on in the document (Poortvliet et al. 2020). Efficacy content that was included in the SPM tended to refer to actions yet to be taken, rather than evidence of past successes. This issue goes wider than the IPCC, suggesting it is a pervasive issue across the landscape of climate engagement. For instance, content analysis of US news media reports shows that information about climate impacts and actions is rarely combined into the same broadcast, and that efficacy-relevant information is inconsistently communicated, with both positive and negative efficacy cues (Hart and Feldman 2014). Similarly, climate change campaigns often fail to integrate appeals towards the range of threat and coping appraisals, and are especially lacking in response-efficacy appeals (Cismaru et al. 2011). And on the ground, members of the public have perceived official bodies involved in managing climate-related risks, such as flooding, to inhibit their capacity to engage in protective actions (WalkerSpringett et al. 2017). 
Although communicating information about the threats posed by climate change is necessary and further work is needed to highlight the personal relevance of impacts to publics (Brügger et al. 2015), this is alone unlikely to generate a sense of empowerment. While there is evidence that public concern about climate change has increased in recent years in countries like the UK, and collective climate action is perceived to have value (Steentjes et al. 2020), other research broadly suggests that efficacy beliefs have been neglected. For instance, survey data suggests that both self- and collective-efficacy towards climate action are broadly limited across European countries (Fisher et al. 2018; Poortinga et al. 2018). In the USA, only a third of citizens appear to believe they can substantially influence elected officials' policy decisions on climate change (Leiserowitz et al. 2019). Furthermore, American citizens perceive personal climate actions to be easier but ineffective, and collective and governmental actions as more effective but difficult (Crosman et al. 2019). Many citizens also fail to appreciate the impact of different actions, such as air travel and meat consumption (Wynes et al. 2020). Thus, there appears to be a great need to address these 'efficacy gaps' more thoroughly in communications practices.

While a pervasive issue in climate engagement, as a globally significant communicator of climate change through its reports and engagement, the IPCC, both as individual scientists and as a collective body, can be a key voice addressing efficacy. However, it appears that only in draft communications strategy has the IPCC considered coordinating a possible second focus on 'learning about and empowering people to deal with climate change' alongside its core function of science dissemination (IPCC 2010: 3). This second focus should now be developed further and to help equip communicators with the skills to address efficacy the next sections provide a range of practical recommendations.

\section{How efficacy can be addressed by climate communicators}

\subsection{Messages appealing to efficacy}

Climate communications that appeal to efficacy, rather than communicate solely about threats posed by climate change, tend to be more effective. Through message testing with participants in Beijing, China, Xue et al. (2016) found that high-threat, high-efficacy messages about climate change elicited higher levels of perceived efficacy in viewers, compared to high-threat, low-efficacy messages. The high-efficacy message was associated with higher levels of danger control processing (e.g. intentions to seek more information and take action) and lower levels of fear control processing (e.g. message rejection and threat denial). Similarly, Kievik and Gutteling (2011) tested the effects of high-/low-threat and high-/low-efficacy messages on Dutch citizens' information-seeking and protective actions related to flooding. Participants who viewed news stories appealing to self-efficacy ('you can easily perform this') and response-efficacy ('this behaviour is successful in mitigating the threat') had greater intentions for information-seeking and protective action than those who did not. In a US study, Hart and Feldman (2016b) found that exposure to a single news story that evoked positive internal-efficacy information increased internal-efficacy (i.e. one's sense that they can understand politics and act effectively in the political realm) and, in turn, increased intended political engagement with climate change. Conversely, exposure to negative efficacy messages reduced participants' internal-efficacy and intended political engagement. Furthermore, Kotcher et al. (2021) show through a large-scale study in the USA that messages combining information about the consequences of impacts, solutions, 
and calls to action motivate climate advocacy behaviour. While all three message aspects enhanced motivation, solution-oriented information was the most influential overall.

In terms of evoking response-efficacy, Reynolds et al. (2020) analysed a range of studies where policy effectiveness has been communicated to participants. Results clearly demonstrated that communicating the effectiveness of policies can bolster support, while communicating policy ineffectiveness can reduce support. At the individual level, Dittrich et al. (2016) found that participation in flood action groups can increase adoption of floodgates and flood warnings, when information about these actions is provided. Individual willingness to adopt measures was associated with tailored information provision, which increased a sense of confidence in, and belief in the effectiveness of, the protective actions.

Studies testing collective-efficacy appeals are less common, yet similar effects have been demonstrated. An experiment conducted by Jugert et al. (2016) showed that communicating information about young people working together to initiate environmental projects increased participants' pro-environmental intentions by increasing perceptions of collective-efficacy and self-efficacy.

Together, these studies suggest that communicators should seek to balance threatening information about climate change with appeals to efficacy, to empower people to respond to climate change. To do this, McLoughlin (2021) suggests that climate communicators should consider the form of response that is required (i.e. individual, policy, or collective) to inform the type of efficacy that should be addressed as a priority (i.e. self-, response-, or collective-efficacy, respectively). Table 1 gives examples of the sort of language that IPCC communicators may adopt to evoke efficacy. These efficacy messages are likely to perform well in combination with other recommendations for climate communication - such as addressing the health risks of climate change and incorporating social norms appeals, which highlight where many other people are already supportive of policies or are taking actions to reduce climate risks (Kotcher et al. 2021; McLoughlin 2021).

\subsection{Vicarious and social learning}

Bandura (1994) explains that witnessing other people's successes can facilitate the belief that one also has the capacity to overcome similar challenges. In this way, Bubeck et al. (2018) found that the social environment (i.e. the actions of family and neighbours) strongly influenced people's coping appraisals related to flood protection. Other work has found that indirect, social experience of flooding (i.e. witnessing friends or family negotiating the challenges of flooding) increases willingness to adopt property-level flood protection (Thistlethwaite et al. 2018). This peer-to-peer learning also has overlap with the welldocumented influence of social norms (i.e. the common actions and beliefs of others) on environmental behaviour (see Keizer and Schultz 2013). Evidence shows that norms can express influence via the mechanism of efficacy. Seebauer and Babcicky (2020) found a strong and consistent effect of social norms on self-efficacy beliefs and, in turn, protective responses to flooding, especially for actions that were observable by others. Together, this suggests that awareness of the social environment can strongly influence one's own actions by influencing efficacy beliefs.

To help facilitate vicarious learning effects, IPCC communicators can use examples of other people successfully taking action on climate change and overcoming obstacles. Bandura (1994) notes that these effects are more likely to occur when the experiences are of a person viewed as similar to oneself. Therefore, communicators may do well to share examples tailored to audiences being engaged with (e.g. successes that are geographically 


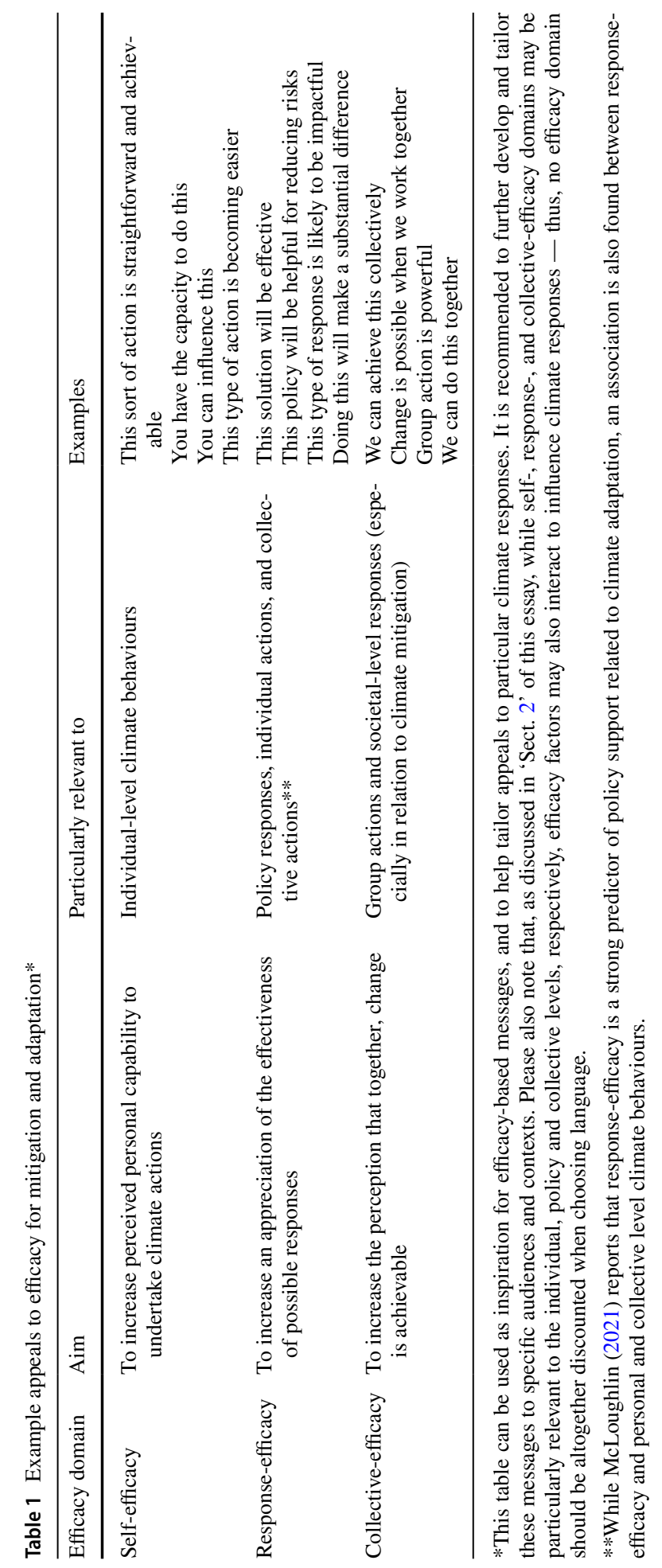


proximate or experienced by members of a shared group). For instance, in workshops designed to increase Women's Institute members' efficacy to communicate about UK climate impacts, participants were encouraged to share examples of successful actions they had taken to communicate climate change, which were brought together into a practical guidebook (see Shaw 2019). Effects may also be amplified through action-based storytelling approaches (De Meyer et al. 2020), given narratives about climate change can be more engaging and memorable than other formats (Dahlstrom 2014). Again, given the role of social norms here, social learning may also be encouraged by highlighting where adaptive actions are being taken by most other people (see Keizer and Schultz 2013).

\subsection{Visuals and imagery}

Images used to convey information about climate change can also impact upon audiences' threat and coping appraisals. Past research has shown that while images of impacts (e.g. melting ice caps, flooding, and wildfires) can increase the perceived salience of climate change, such imagery may also reduce self-efficacy, leaving audiences feeling overwhelmed, rather than motivated to respond to climate change (O'Neill et al. 2013; O'Neill and Nicholson-Cole 2009). On the other hand, images of climate change actions and solutions can bolster individuals' sense of self-efficacy (Metag et al. 2016; O'Neill et al. 2013; O'Neill and Nicholson-Cole 2009). For instance, Hart and Feldman (2016a) have shown that solution-focused imagery (e.g. solar panels) and texts about actions to address climate change boosted individuals' perceived efficacy, while images of people engaging in climate solutions can evoke greater efficacy than depictions of the health impacts of climate change (McLoughlin 2021; McLoughlin and Corner 2020). In a similar vein, Chapman et al. (2016) report that images of solutions produced positive affective responses. While not all research has found that impact imagery reduces self-efficacy beliefs (e.g. Hart and Feldman (2016a), this research base clearly suggests that IPCC communications could increase efficacy by making greater use of imagery depicting solutions and people taking actions.

\subsection{Mastery experiences}

Finally, it is worth considering 'mastery experiences', given these are often reported to be the most effective way to increase self-efficacy (Bandura 1994; Koletsou and Mancy 2011). When individuals experience success through engaging in actions to overcome challenges, this can increase efficacy, while experiencing failures can decrease efficacy. For instance, Seebauer and Babcicky (2020) report that personal competencies gained from experience of flooding action and other life challenges (e.g. fire and burglary) increased self-efficacy in relation to flood mitigation behaviour, supporting protective action. Similarly, people's sense of satisfaction from engaging in different pro-environmental actions (e.g. tree planting, eating locally grown food, and sustainable transport) can influence their beliefs about the importance, duration, and costs of these actions (Ertz and Sarigöllü 2019). Furthermore, Swim and Fraser (2013) show that through a skills development programme which offered a supportive environment, educators felt more confident to engage with others about climate change. Climate education interventions can also increase people's sense of efficacy to engage with others (Geiger et al. 2017).

In this sense, De Meyer et al. (2020) argue that the power of self-persuasion by engaging in actions (i.e. the idea that 'actions drive beliefs') is undervalued in climate engagement, 
and thus emphasise the importance of action-based climate communications. Additionally, engaging with individuals via participatory engagement approaches (e.g. co-production) allows for active, rather than passive engagement (see Howarth 2019), and may act as a form of mastery experience for stakeholders in and of itself. While learning via mastery experience largely extends beyond the scope of what IPCC communicators may achieve alone (structural, financial, and other hard interventions may better facilitate many mastery opportunities), they may be able to co-produce mastery opportunities. For instance, IPCC scientists could work with different stakeholders to deliver climate education, design and co-facilitate skills training in mitigation and adaptation, highlight opportunities for individuals to engage in adaptive actions, and encourage individuals to reflect on their past successes in relevant domains.

\section{Overcoming hesitation to appeal to efficacy}

Climate scientists are trusted more than most other communicators of climate change (Wang et al. 2020). Despite this, IPCC scientists may be reluctant to appeal to efficacy in the ways described above, due to a desire to maintain a neutral stance in relation to policy advocacy. For instance, Gundersen (2020), who interviewed IPCC scientists in Norway, found reluctance amongst the interviewees to speak up about climate change publicly because they were afraid to risk their perceived objectivity and credibility.

However, hesitation in appealing to efficacy may be overcautious for two reasons. First, communicating to bolster efficacy is a proactive, motivational stance, which is not anticipated to undermine perceptions of scientific credibility. Research has found that the credibility of scientists does not suffer when they advocate the need for greater climate action (i.e. non-policy specific communication) or when discussing the pros and cons of specific climate policies - and was only diminished when advocating certain specific policies, like nuclear power (Kotcher et al. 2017). Other work finds that advocacy of specific policies implicates perceived objectivity, but not credibility or trustworthiness (Cologna et al. 2021). Although efficacy appeals may of course be policy-relevant, or depict specific types of responses, putting these principles into practice does not require communicators to engage in advocacy of specific policies, unless they wish to. Additionally, communicating how effective responses will be, or highlighting that individuals and groups have the capacity to carry out certain actions, is not the same as advocating for specific responses. It is an encouraging, advisory position, but one that is subtly different to policy advocacy.

Second, despite this, there is also clear evidence that people wish for scientists to go beyond their current engagement practices on climate change. A large-scale study found that members of the public in Germany and the USA, as well as other climate scientists, would prefer scientists to adopt fewer neutral stances when communicating with the media and policymakers about climate change (Cologna et al. 2021). A study with climate communication practitioners in the UK also highlighted that climate scientists, journalists, and other communicators believe it is important to nurture a sense of agency and empowerment through their communications practices (McLoughlin et al. 2018). Thus, it is likely that efficacy-oriented communication will be accommodated.

Given perceived motivations behind scientists' engagement are also a key factor in public perceptions of credibility, IPCC scientists could also be transparent about their intentions (Beall et al. 2017; Nelson and Vucetich 2009). To be wholly clear, evoking efficacy is not about persuasion; it is about communicating climate information in a way that fully 
acknowledges and respects the psychological needs of the individuals being engaged with. It is about reducing the risk of negative wellbeing outcomes for audiences, by providing 'a route out' - helping people feel confident to proactively cope with the threats posed by climate change. In fact, due to this, it is more problematic not to appeal to efficacy when communicating potentially threatening information, given the clear risks of negative and avoidant coping responses when efficacy beliefs are low (Peters et al. 2013). In this sense, communicating efficacy is akin to serving the public, an intention which is associated with credibility in the public mind (Beall et al. 2017). An efficacy-focused approach is also about properly respecting that all individuals engaged with are 'agents of change' in the transition towards a climate resilient planet (O'Brien 2018: 157).

If further caution is desirable while appealing to efficacy, communicators may also (a) discuss a range of response options without focusing on any one response in particular, (b) clarify that they are not endorsing any policy or action discussed, (c) caveat efficacy appeals by stating that it is for individuals to decide how to act and what to support. And very cautious communicators could, without discussing actions explicitly, (d) encourage people to reflect on the types of responses they feel personally able to engage with, what they feel is achievable together, and feel is most likely to be effective, and use that information to guide their decision making.

\section{Conclusion and recommendations: Suggestions for IPCC scientists and other climate change communicators}

While there is clear and consistent evidence of the importance of efficacy variables in promoting adaptive responses to climate change, efficacy-evoking information has often been neglected, treated as an afterthought, or left out altogether in climate change communications. Thus, there is now a great need to change course in climate engagement, to ensure that a sense of threat is balanced with efficacy. As laid out in this essay, communicators have a range of practical options available to do so. The recommendations are now summarised in relation to the IPCC.

In public and stakeholder facing activities, IPCC scientists and communications staff should:

1. Use language that aims to increase a sense of self-, response-, and collective-efficacy (see Table 1) alongside communicating the human health risks of climate impacts and highlighting where climate actions are socially normative.

2. Use effective visuals that balance depictions of the impacts of climate change with imagery showing people engaging in climate solutions. ${ }^{2}$

3. Provide examples and stories of people successfully taking actions to address climate change and overcoming obstacles, tailoring these examples to audiences where possible.

4. (Co)-facilitate opportunities for mastery experiences where possible, to enable stakeholders to feel confident about implementing different actions and responses.

\footnotetext{
${ }^{2}$ A useful resource for evidence-based climate change imagery is www.climatevisuals.org, which includes a 'solution' gallery.
} 
In objective, scientific reports, it may not be appropriate to include efficacy-framed language. However, in reports and SPMs specifically, IPCC authors may usefully:

1. Increase emphasis on the effectiveness of specific response options (i.e. providing information to inform readers' response-efficacy related to solutions).

2. Do more to communicate which actions are achievable and straightforward for policymakers, individuals, and groups to take (i.e. providing information that can inform readers about self-efficacy and collective-efficacy).

3. Overall, ensure content about the threats posed by climate change impacts are sufficiently balanced with efficacy-relevant, solution-oriented information.

Finally, in relation to the IPCC's overarching communications:

1. Include efficacy appeals (as above) in press releases, media content, social media posts, and other public-facing communication.

2. Revisit the aim of 'empowering people to deal with climate change' alongside the core function of science dissemination (IPCC 2010: 3).

Given its global reach, the IPCC collectively can be a significant force in nurturing efficacy, alongside science dissemination. However, other communicators must also play a role in building efficacy too. While IPCC scientists may engage with localised groups in some of their capacities, tailoring to specific audiences may not always be achievable in some of the IPCC's communication practices (e.g. reports and press releases). Other communicators (e.g. national and local governments, journalists, health professionals, community members, and creative practitioners) who have different target audiences, values, and goals may be able to administer more targeted appeals to efficacy. As discussed by McLoughlin (2021), it appears that efficacy appeals may be delivered particularly effectively by trusted, in-group communicators from within shared value groups. Therefore, IPCC scientists and communications staff should also work with a range of different communicators, stakeholders, and interest groups as intermediaries to help co-produce efficacy.

In these ways, by appealing to efficacy more fulsomely, the IPCC, climate scientists, and other communicators can certainly empower more people to cope with the threats posed by climate change.

Acknowledgements Niall McLoughlin (NM) would like to thank the three anonymous reviewers for their helpful and detailed comments in relation to this essay.

Author contribution NM had the idea for this essay, performed the literature search, drafted, and revised the manuscript. No other authors contributed to the preparation of this manuscript.

Data availability Not applicable.

Code availability Not applicable.

\section{Declarations}

Ethics approval Not applicable.

Consent to participate Not applicable.

Consent for publication Not applicable. 
Conflict of interest Nothing to declare. For transparency, NM would like to note he is a Research Associate of Climate Outreach. NM prepared this manuscript independently, with no involvement from Climate Outreach.

Additional declarations for articles in life science journals that report the results of studies involving humans and/or animals Not applicable.

Open Access This article is licensed under a Creative Commons Attribution 4.0 International License, which permits use, sharing, adaptation, distribution and reproduction in any medium or format, as long as you give appropriate credit to the original author(s) and the source, provide a link to the Creative Commons licence, and indicate if changes were made. The images or other third party material in this article are included in the article's Creative Commons licence, unless indicated otherwise in a credit line to the material. If material is not included in the article's Creative Commons licence and your intended use is not permitted by statutory regulation or exceeds the permitted use, you will need to obtain permission directly from the copyright holder. To view a copy of this licence, visit http://creativecommons.org/licenses/by/4.0/.

\section{References}

Bandura A (1994) Self-efficacy. In V. S. Ramachaudran (Ed.), Encyclopedia of human behavior (Vol. 4, pp. 71-81). Academic Press. http://www.des.emory.edu/mfp/BanEncy.html

Bandura A (2018) Toward a psychology of human agency: pathways and reflections. Perspect Psychol Sci 13(2):130-136. https://doi.org/10.1177/1745691617699280

Beall L, Myers TA, Kotcher JE, Vraga EK, Maibach EW (2017) Controversy matters: impacts of topic and solution controversy on the perceived credibility of a scientist who advocates. PLoS ONE 12(11):e0187511. https://doi.org/10.1371/journal.pone.0187511

Bostrom A, Hayes AL, Crosman KM (2019) Efficacy, action, and support for reducing climate change risks. Risk Anal 39(4):805-828. https://doi.org/10.1111/risa.13210

Brügger A, Dessai S, Devine-Wright P, Morton TA, Pidgeon NF (2015) Psychological responses to the proximity of climate change. Nat Clim Chang 5(12):1031-1037

Bubeck P, Botzen WJ, Laudan J, Aerts JCJH, Thieken AH (2018) Insights into flood-coping appraisals of protection motivation theory: empirical evidence from Germany and France. Risk Anal 38(6):12391257. https://doi.org/10.1111/risa.12938

Chapman DA, Corner A, Webster R, Markowitz EM (2016) Climate visuals: a mixed methods investigation of public perceptions of climate images in three countries. Glob Environ Change 41:172-182

Cismaru M, Cismaru R, Ono T, Nelson K (2011) "Act on climate change": an application of protection motivation theory. Soc Mark Q 17(3):62-84. https://doi.org/10.1080/15245004.2011.595539

Cologna V, Knutti R, Oreskes N, Siegrist M (2021) Majority of German citizens, US citizens and climate scientists support policy advocacy by climate researchers and expect greater political engagement. Environ Res Lett 16(2):24011. https://doi.org/10.1088/1748-9326/abd4ac

Crosman KM, Bostrom A, Hayes AL (2019) Efficacy foundations for risk communication: how people think about reducing the risks of climate change. Risk Anal 39(10):2329-2347. https://doi.org/10.1111/risa. 13334

Dahlstrom MF (2014) Using narratives and storytelling to communicate science with nonexpert audiences. Proc Natl Acad Sci USA 111(Supplement 4):13614-13620. https://doi.org/10.1073/pnas.1320645111

De Meyer K, Coren E, McCaffrey MS, Slean C (2020) Transforming the stories we tell about climate change: from "issue" to "action.” Environ Res Lett. https://doi.org/10.1088/1748-9326/abcd5a

Dittrich R, Wreford A, Butler A, Moran D (2016) The impact of flood action groups on the uptake of flood management measures. Clim Change 138:471-489

Doherty KL, Webler TN (2016) Social norms and efficacy beliefs drive the alarmed segment's public-sphere climate actions. Nat Clim Chang 6(9):879-884

Ertz M, Sarigöllü E (2019) The behavior-attitude relationship and satisfaction in proenvironmental behavior. Environ Behav 51(9-10):1106-1132. https://doi.org/10.1177/0013916518783241

Fisher, S., Fitzgerald, R., \& Poortinga, W. (2018). Climate change-climate change social divisions in beliefs and behaviour. In D. Phillips, J. Curtice, M. Phillips, \& J. Perry (Eds.), British social attitudes: the 35th report. The National Centre for Social Research. https://www.bsa.natcen.ac.uk/media/39251/ bsa35_climate_change.pdf

Floyd DL, Prentice-Dunn S, Rogers R (2000) A meta-analysis of research on protection motivation theory. J Appl Social Pyschol 30(2):407-429 
Fox-Rogers L, Devitt C, O’Neill E, Brereton F, Clinch JP (2016) Is there really "nothing you can do"? Pathways to enhanced flood-risk preparedness. J Hydrol 543:330-343

Geiger N, Swim JK, Fraser J (2017) Creating a climate for change: interventions, efficacy and public discussion about climate change. J Environ Psychol 51:104-116. https://doi.org/10.1016/j.jenvp.2017.03.010

Gregersen T, Doran R, Böhm G, Poortinga W (2021) Outcome expectancies moderate the association between worry about climate change and personal energy-saving behaviors. PLoS ONE 16(5):e0252105. https://doi.org/10.1371/JOURNAL.PONE.0252105

Gundersen T (2020) Value-free yet policy-relevant? The normative views of climate scientists and their bearing on philosophy. Perspect Sci 28(1):89-118. https://doi.org/10.1162/posc_a_00334

Hart PS, Feldman L (2014) Threat without efficacy? Climate change on U.S. network news. Sci Comm 36(3):325-351. https://doi.org/10.1177/1075547013520239

Hart PS, Feldman L (2016a) The impact of climate change-related imagery and text on public opinion and behavior change. Sci Commun 38(4):415-441

Hart PS, Feldman L (2016b) The influence of climate change efficacy messages and efficacy beliefs on intended political participation. PLoS One 11(8):e0157658

Howarth C (2019) Resilience to climate change: communication, collaboration and co-production. Springer

IPCC. (2010). Communications strategy progress report and draft strategy (submitted by the IPCC Secretariat) thirty-second session of the IPCC Busan, 11-14 October 2010 IPCC-XXXII/Doc. 21 (4.X.2010) Agenda Item: 9 ENGLISH ONLY . https://www.ipcc.ch/site/assets/uploads/2018/03/doc21_p32_ communication_strategy.pdf

Jugert P, Greenaway KH, Barth M, Büchner R, Eisentraut S, Fritsche I (2016) Collective efficacy increases pro-environmental intentions through increasing self-efficacy. J Environ Psychol 48:12-23. https://doi. org/10.1016/j.jenvp.2016.08.003

Keizer, K., \& Schultz, P. W. (2013). Social norms and pro enviornmental behaviour. In J. I. M. De Groot D \& Thørgerson (Eds.), Enviornmental Psychology: An Introduction (pp. 153-163). BPS.

Kievik M, Gutteling JM (2011) Yes, we can: motivate Dutch citizens to engage in self-protective behavior with regard to flood risks. Nat Hazards 59(3):1475

Koletsou, A., \& Mancy, R. (2011). Which efficacy constructs for large-scale social dilemma problems? Individual and collective forms of efficacy and outcome expectancies in the context of climate change mitigation. Source: Risk Management 13(4), 184-208. https://doi.org/10.1057/rm.2011

Kotcher JE, Feldman L, Luong KT, Wyatt J, Maibach E (2021) Advocacy messages about climate and health are more effective when they include information about risks, solutions, and a normative appeal: evidence from a conjoint experiment. The Journal of Climate Change and Health 3:100030. https://doi. org/10.1016/J.JOCLIM.2021.100030

Kotcher JE, Myers TA, Vraga EK, Stenhouse N, Maibach EW (2017) Does engagement in advocacy hurt the credibility of scientists? Results from a randomized national survey experiment. Environ Commun 11(3):415-429. https://doi.org/10.1080/17524032.2016.1275736

Leiserowitz, A., Maibach, E., Rosenthal, S., Kotcher, J., Bergquist, P., Gustafson, A., Ballew, M., \& Goldberg, M. (2019). Climate activism: beliefs, attitudes, and behaviors. In Yale program on climate change communication. Yale University and George Mason University. https://climatecommunication.yale. edu/wp-content/uploads/2020/02/global-warming-activism-november-2019.pdf

Lorenzoni I, Nicholson-Cole S, Whitmarsh L (2007) Barriers perceived to engaging with climate change among the UK public and their policy implications. Global Environmental Change-Human and Policy Dimensions 17(3-4):445-459

Lubell M (2002) Environmental activism as collective action. Environ Behav 34(4):431-454. https://doi. org/10.1177/00116502034004002

McLoughlin, N. (2021). Communicating adaptation: using psychological insights to facilitate adaptive responses to climate change impacts [University of Bath]. https://ethos.bl.uk/OrderDetails.do?uin=uk. bl.ethos. 834269

McLoughlin, N., \& Corner, A. (2020, February 18). The air that we breathe I climate visuals. Climate Visuals. https://climatevisuals.org/blogs/air-we-breathe-climate-and-health-imagery

McLoughlin, N., Corner, A., Capstick, S., Richardson, H., Bell, A., Muller, C., \& Illingworth, S. (2018). Climate communication in practice: how are we engaging the UK public on climate change?

Metag, J., Schäfer, M. S., Füchslin, T., Barsuhn, T., \& Kleinen-von Königslöw, K. (2016). Perceptions of climate change imagery: evoked salience and self-efficacy in Germany, Switzerland, and Austria (Vol. 38).

Nelson MP, Vucetich JA (2009) On advocacy by environmental scientists: what, whether, why, and how. Conserv Biol 23(5):1090-1101. https://doi.org/10.1111/j.1523-1739.2009.01250.x 
O'Brien, K. (2018). Is the $1.5^{\circ} \mathrm{C}$ target possible? Exploring the three spheres of transformation. In Current opinion in environmental sustainability (Vol. 31, pp. 153-160). Elsevier B.V. https://doi.org/10.1016/j. cosust.2018.04.010

O'Neill S, Boykoff M, Niemeyer S, Day SA (2013) On the use of imagery for climate change engagement. Glob Environ Change 23(2):413-421

O'Neill S, Nicholson-Cole S (2009) "Fear won't do it" promoting positive engagement with climate change through visual and iconic representations. Sci Commun 30(3):355-379

Peters GJY, Ruiter RAC, Kok G (2013) Threatening communication: a critical re-analysis and a revised meta-analytic test of fear appeal theory. Health Psychol Rev 7(SUPPL1):S8-S31. https://doi.org/10. 1080/17437199.2012.703527

Poortinga, W., Fisher, S., Böhm, G., Steg, L., Whitmarsh, L., \& Ogunbode, C. (2018). European attitudes to climate change and energy: topline results from round 8 of the European Social Survey.

Poortvliet PM, Niles MT, Veraart JA, Werners SE, Korporaal FC, Mulder BC (2020) Communicating climate change risk: a content analysis of ipcc's summary for policymakers. Sustainability (switzerland) 12(12):4861. https://doi.org/10.3390/SU12124861

Reynolds JP, Stautz K, Pilling M, van der Linden S, Marteau TM (2020) Communicating the effectiveness and ineffectiveness of government policies and their impact on public support: a systematic review with meta-analysis. Royal Society Open Science 7(1):190522. https://doi.org/10.1098/rsos.190522

Seebauer, S., \& Babcicky, P. (2020). The sources of belief in personal capability: antecedents of self-efficacy in private adaptation to flood risk. Risk Analysis, risa.13531. https://doi.org/10.1111/risa.13531

Shaw, C. (2019). Communicating climate impacts through adaptation. Tips and activities for women's institute climate ambassadors. https://climateoutreach.org/resources/guide-communicating-climate-impac ts-through-adaptation-wi/

Steentjes, K., Demski, C., Seabrook, A., Corner, A., \& Pidgeon, N. (2020). British public perceptions of climate risk, adaptation options and resilience (RESiL RISK): topline findings of a GB survey conducted in October 2019.

Swim JK, Fraser J (2013) Fostering hope in climate change educators. Journal of Museum Education 38(3):286-297. https://doi.org/10.1080/10598650.2013.11510781

Swim JK, Fraser J (2014) Zoo and aquarium professionals' concerns and confidence about climate change education. J Geosci Educ 62(3):495-501. https://doi.org/10.5408/13-048.1

Thaker J, Maibach E, Leiserowitz A, Zhao X, Howe P (2016) The role of collective efficacy in climate change adaptation in India. Wea Climate Soc 8(1):21-34

Thistlethwaite J, Henstra D, Brown C, Scott D (2018) How flood experience and risk perception influences protective actions and behaviours among Canadian homeowners. Environ Manage 61(2):197-208. https://doi.org/10.1007/s00267-017-0969-2

Truelove HB, Parks C (2012) Perceptions of behaviors that cause and mitigate global warming and intentions to perform these behaviors. J Environ Psychol 32(3):246-259

van Valkengoed A, Steg L (2019) Meta-analyses of factors motivating climate change adaptation behaviour. Nat Clim Chang 9(2):158

Walker-Springett, K., Butler, C., \& Adger, W. N. (2017). Wellbeing in the aftermath of floods. Health and Place, 43(October 2016), 66-74.

Wang, S., Corner, A., \& Nicholls, J. (2020). Britain talks climate: a toolkit for engaging the British public on climate change.

Witte K, Allen M (2000) A meta-analysis of fear appeals: implications for effective public health campaigns. Health Educ Behav 27(5):591-615

Wynes S, Zhao J, Donner SD (2020) How well do people understand the climate impact of individual actions? Clim Change 162(3):1521-1534. https://doi.org/10.1007/s10584-020-02811-5

Xue W, Hine DW, Marks ADG, Phillips WJ, Nunn P, Zhao S (2016) Combining threat and efficacy messaging to increase public engagement with climate change in Beijing. China Climatic Change 137(12):43-55. https://doi.org/10.1007/s10584-016-1678-1

Publisher's Note Springer Nature remains neutral with regard to jurisdictional claims in published maps and institutional affiliations. 